\title{
DETEKSI WAJAH MENGGUNAKAN HIDDEN MARKOV MODEL (HMM) BERBASIS MATLAB
}

\author{
Nur Widya Pratiwi ${ }^{1}$, Fauziah $^{2}$, Septi Andryana ${ }^{3}$, Aris Gunaryati ${ }^{4}$ \\ Program Studi Informatika, Universitas Nasional ${ }^{1,2,3,4}$ \\ nurwidyapratiwi@gmail.com¹, fauziah@civitas.unas.ac.id ${ }^{2}$, septi.andryana@civitas.unas.ac.id ${ }^{3}$, \\ aris.gunaryati@civitas.unas.ac.id ${ }^{4}$
}

\begin{abstract}
Abstrak
Wajah merupakan bagian tubuh yang dapat dideteksi, hal ini yang membuat wajah menjadi dasar sistem pendeteksi, sistem dapat mendeteksi objek berupa wajah dari masukan citra. Untuk itu akan dikembangkan sebuah sistem pendeteksi wajah menggunakan metode Hidden Markov Model (HMM). Sistem ini merupakan teknologi dari komputer yang memungkinkan untuk mengidentifikasi atau memverifikasi wajah seseorang melalui sebuah gambar. Cara kerja sistem deteksi wajah ini ialah dengan mencocokkan sebuah gambar wajah dengan gambar wajah yang tersimpan di file. Terbarunya dari penelitian ini ialah pendeteksian dapat menggunakan gambar atau foto yang berwarna maupun hitam putih daripada penelitian sebelumnya yang hanya menggunakan gambar atau foto hitam putih, pembuatan deteksi wajah ini menggunakan software MATLAB untuk programnya dan Guide MATLAB untuk mendesain deteksi wajah. Dari percobaan dan pengujian yang dilakukan, aplikasi dapat mendeteksi citra wajah dengan tingkat keberhasilan sampai 95.9\% Hal ini membuktikan aplikasi ini cukup baik dalam pengenalan wajah.
\end{abstract}

Kata Kunci : Deteksi wajah, Hidden Markov Model (HMM), MATLAB, Gambar, Citra

\begin{abstract}
Face is a part of the body that can be detected. It makes face the basis of a detection system. The system can detect the object of face from an input image. The research develops the face detection system using Hidden Markov Model (HMM) method. The system is a computer technology allowing identification or verification of a person's face through an image. The workings of face detection system is by matching a face image with face image stored in file. Unlike the previous system that can only detect black-and-white pictures or images, the system created in this research is an update that can detect black-and-white and color pictures or images. This face detection system uses MATLAB software for its program and Guide MATLAB for its design. From the experiments and tests performed, the application can detect face image with success rate up to 95.9\%. This proves the tool is quite good in face recognition or detection.
\end{abstract}

Keywords : Face detection, Hidden Markov Model (HMM), MATLAB, Picture, Image

\section{PENDAHULUAN}

Pengenalan wajah merupakan suatu benda yang sudah terdeteksi sebagai wajah atau bukan, lalu diketahui siapa yang terdapat pada wajah tersebut[13]. Sebelum proses pengenalan wajah dilakukan pendeteksian wajah pada suatu gambar. Deteksi wajah adalah proses pengenalan wajah yang mencari fitur citra sehingga mengenali pola[14]. Pada saat ini deteksi wajah dengan aplikasi sangat diperlukan untuk mengatasi masalah identifikasi pelaku kejahatan, sistem keamanan, dan memproses pola dan citra[15]. Deteksi wajah merupakan salah satu tahap awal yang sangat penting sebelum dilakukan proses Hidden Markov Model (HMM)[1]. Proses ini dalam gambaran visual dapat diimplementasikan kedalam aplikasi MATLAB yang mencakup pendeteksian wajah menggunakan metode Hidden Markov Model (HMM)[2]. Prinsip kerja sistem secara keseluruhan adalah pengenalan beberapa gambar wajah dengan berbagai ekspresi yang berfungsi sebagai input dengan gambar wajah yang disimpan dalam database menggunakan algoritma atau metode Hidden Markov 
Model (HMM)[3]. Dalam penelitian ini akan dikembangkan sebuah sistem deteksi wajah menggunakan metode Hidden Markov Model (HMM) dengan aplikasi MATLAB dan desain yang menggunakan Guide MATLAB. Kemudian akan dilakukan perbandingan tingkat akurasi yang menggunakan Hidden Markov Model (HMM) dan system berbasis metode yang lain[4]. Permasalahan dari deteksi wajah ini adalah permasalahan intesitas cahaya untuk mendeteksi wajah pada foto dan bagaimana menilai dan menghitung tingkat akurasi pada deteksi wajah[12]. Tujuan penelitian ini adalah untuk membuat sebuah program deteksi wajah menggunakan metode Hidden Markov Model (HMM) dengan hasil foto sendiri memanfaatkan MATLAB dan Guide MATLAB[5].

\section{METODE PENELITIAN}

Pada bagian ini, metode Hidden Markov Model (HMM) dikembangkan. Prosedur yang digunakan dalam metode yang diusulkan dijelaskan sebagai berikut.

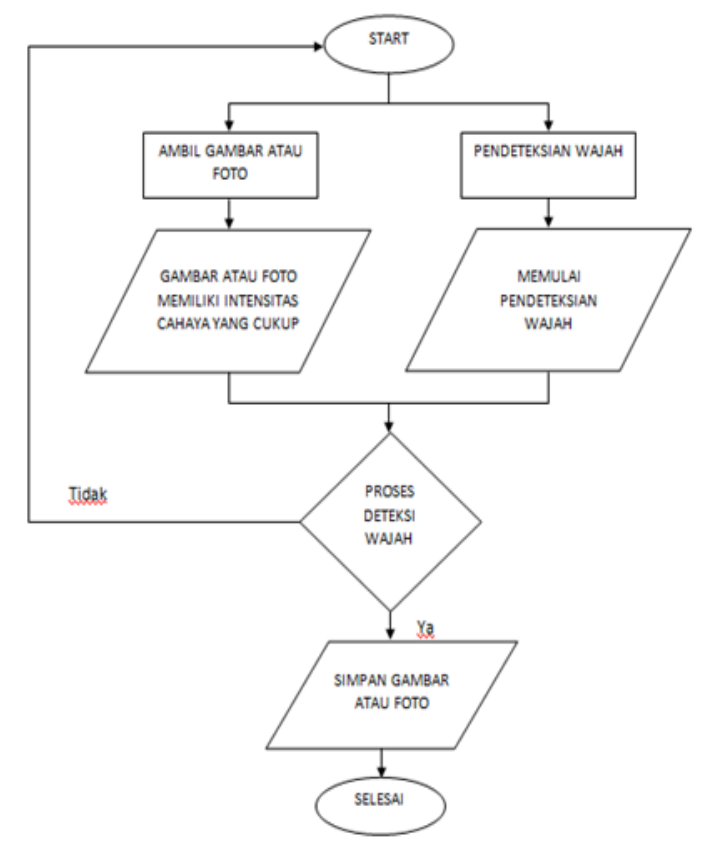

Gambar 1. Diagram Alur Deteksi Wajah Menggunakan HMM
Pada gambar 1, terlihat tahapan-tahapan perancangan aplikasi dari identifikasi masalah yang sedang dihadapi setelah kondisi teridentifikasi tercapai kemudian lakukan klasifikasi masalah terhadap aplikasi yang dibuat, tahap selanjutnya adalah pengumpulan data dari berbagai sumber referensi jurnal, buku, maupun media. Menganalisis data yang sudah didapat dari sumber pengumpulan data, maka perancangan aplikasi sudah dapat dibuat serta dilakukan uji coba terhadap aplikasi yang telah dibuat[9]. Prinsip dasar pengenalan wajah adalah mengutip informasi unik wajah, kemudian diencode dan dibandingkan dengan hasil decode yang sebelumnya dilakukan. Hasil dari Hiddden Markov Model (HMM) kemudian direpresentasikan dalam sebuah aplikasi. Setiap wajah yang direpresentasikan HMM adalah bagaimana cara meguraikan informasi yang relevan dari sebuah citra[6]. Deteksi wajah ini dapat menggunakan gambar atau foto berwarna maupun hitam putih daripada deteksi wajah sebelumnya yang hanya menggunakan gambar atau foto hitam putih 


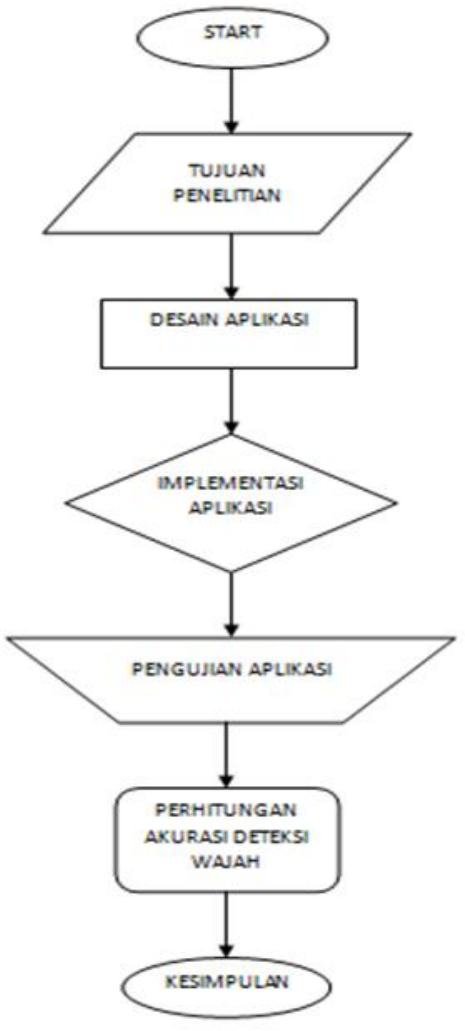

Gambar 2. Diagram Alur Penelitian

Pada gambar 2, menunjukkan tahapan penelitian deteksi wajah. Awalnya menentukan tujuan penelitian lalu membuat desain aplikasi deteksi wajah yang dibuat diaplikasi MATLAB dan diimplementasikan di aplikasi. Setelah diimplementasi, aplikasi deteksi wajah akan diuji dan diperhitungkannya tingkat akurasi pada deteksi wajah tersebut. Pada penelitian ini deteksi wajah akan dikenalkan pada objek deteksi wajah[11].

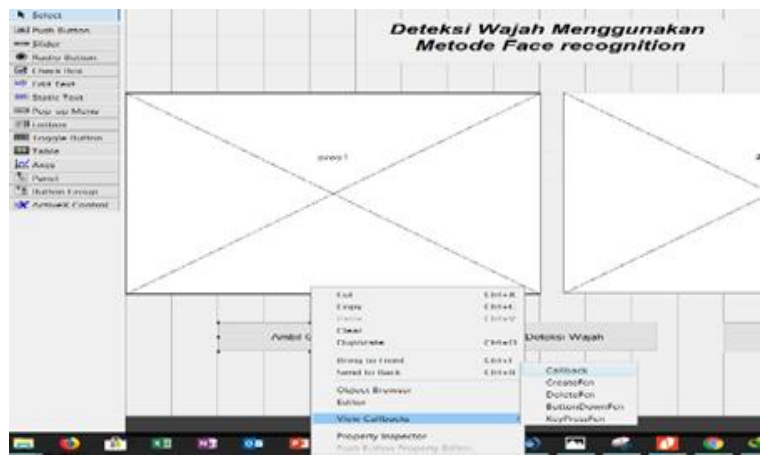

Gambar 3. Button Ambil Gambar
Gambar 3, menunjukkan Button untuk mengambil gambar atau foto dari file yang sudah ada.

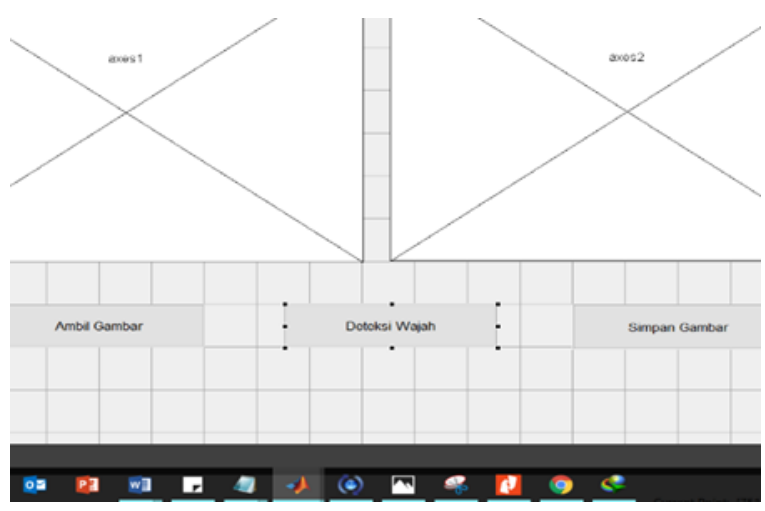

Gambar 4. Button Deteksi Wajah

Gambar 4, adalah Button deteksi wajah untuk mendeteksi wajah yang sudah diambil gambar atau fotonya dari file yang sudah tersedia.

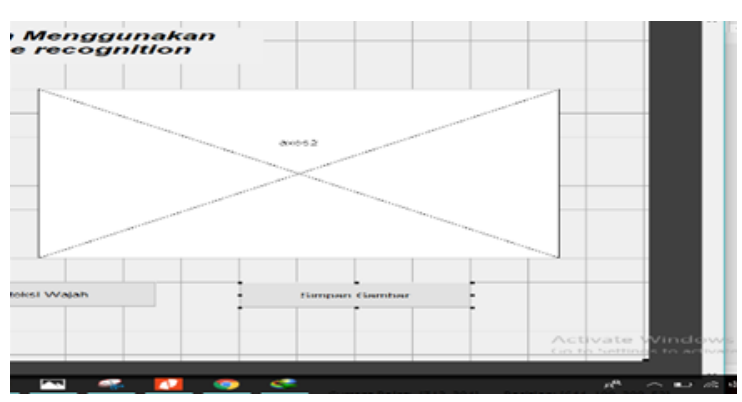

Gambar 5. Button Simpan Gambar

Gambar 5, adalah Button simpan gambar untuk menyimpan gambar wajah yang sudah terdeteksi di file yang sudah tersedia

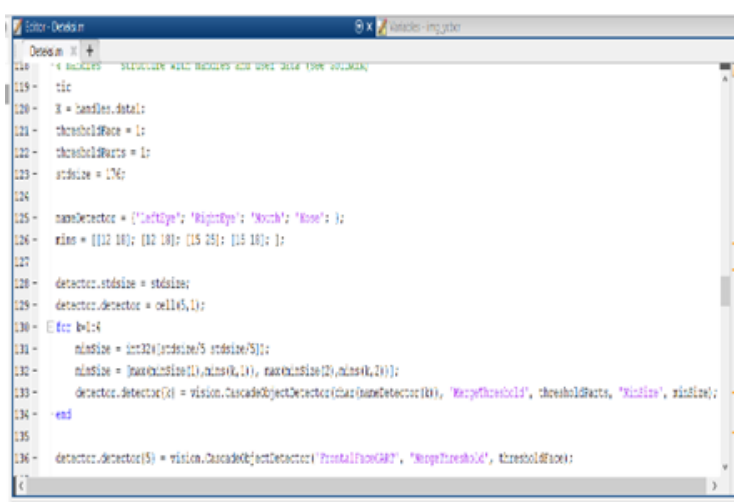

Gambar 6. Sistem Dengan Metode Hidden Markov Model (HMM) 
Gambar 6, menunjukkan program untuk mengembangkan aplikasi atau system pendeteksi wajah dengan metode HMM. Proses deteksi wajah dapat dilakukan dalam beberapa tahap, yaitu proses pembacaan file foto, proses konversi file foto ke dalam format yang diinginkan dan penyiapan data wajah untuk tiap wajah yang sudah dikenali atau dideteksi dalam foto, wajah yang dideteksi dengan kotak dan menyimpan ke dalam file baru[8].

Tabel 1. Deteksi Wajah

\begin{tabular}{|c|c|c|c|}
\hline NO & $\begin{array}{c}\text { Gambar } \\
\text { atau foto } \\
\text { yang } \\
\text { belum } \\
\text { terdeteksi }\end{array}$ & $\begin{array}{c}\text { Gambar } \\
\text { atau foto } \\
\text { yang sudah } \\
\text { terdeteksi }\end{array}$ & Keterangan \\
\hline 1 & & $\begin{array}{c}\text { Objek wajah } \\
\text { dapat } \\
\text { terdeteksi } \\
\text { karena } \\
\text { intensitas } \\
\text { cahaya yang } \\
\text { cukup dan } \\
\text { jarak wajah } \\
\text { dengan } \\
\text { kamera } \\
\text { sesuai }\end{array}$ \\
\hline 2 & & $\begin{array}{c}\text { Objek wajah } \\
\text { tidak dapat } \\
\text { terdeteksi di } \\
\text { karenakan } \\
\text { wajah tidak } \\
\text { menghadap } \\
\text { kearah } \\
\text { kamera }\end{array}$ \\
\hline
\end{tabular}

Wajah yang sudah di deteksi akan disimpan di file yang sudah dibuat dan wajah yang tidak terdeteksi tidak akan bisa tersimpan di file yang sudah dibuat.

\section{HASIL DAN PEMBAHASAN}

Setelah sistem pendeteksi wajah dapat diimplementasikan, selanjutnya akan dilakukan pengujian terhadap sistem tersebut untuk mengetahui tingkat akurasi dari hasilnya.

Berikut tabel pengujian pada deteksi wajah:

Tabel 2. Pengujian Deteksi Wajah

\begin{tabular}{|c|c|c|c|c|}
\hline No & Pengujian & $\begin{array}{l}\text { Jumlah } \\
\text { Wajah } \\
\text { di Foto }\end{array}$ & $\begin{array}{l}\text { Jumlah } \\
\text { Deteksi } \\
\text { Wajah }\end{array}$ & Selisih \\
\hline 1 & 1 & 6 & 5 & 1 \\
\hline 2 & 2 & 7 & 7 & 0 \\
\hline 3 & 3 & 6 & 5 & 1 \\
\hline 4 & 4 & 6 & 6 & 1 \\
\hline 5 & 5 & 5 & 3 & 2 \\
\hline 6 & 6 & 3 & 3 & 0 \\
\hline 7 & 7 & 4 & 4 & 0 \\
\hline 8 & 8 & 11 & 11 & 1 \\
\hline 9 & 9 & 3 & 4 & 1 \\
\hline 10 & 10 & 5 & 5 & 0 \\
\hline 11 & 11 & 2 & 2 & 0 \\
\hline 12 & 12 & 9 & 9 & 0 \\
\hline 13 & 13 & 7 & 6 & 1 \\
\hline 14 & 14 & 6 & 6 & 0 \\
\hline 15 & 15 & 4 & 4 & 0 \\
\hline 16 & 16 & 3 & 3 & 0 \\
\hline 17 & 17 & 15 & 15 & 0 \\
\hline 18 & 18 & 4 & 4 & 0 \\
\hline 19 & 19 & 10 & 10 & 0 \\
\hline 20 & 20 & 6 & 6 & 0 \\
\hline 21 & 21 & 6 & 6 & 0 \\
\hline 22 & 22 & 4 & 4 & 0 \\
\hline 23 & 23 & 2 & 3 & 1 \\
\hline 24 & 24 & 3 & 4 & 1 \\
\hline 25 & 25 & 4 & 4 & 0 \\
\hline 26 & 26 & 9 & 8 & 1 \\
\hline 27 & 27 & 7 & 7 & 0 \\
\hline 28 & 28 & 7 & 6 & 1 \\
\hline 29 & 29 & 3 & 2 & 1 \\
\hline 30 & 30 & 3 & 2 & 1 \\
\hline \multicolumn{2}{|c|}{ Rata - Rata } & 170 & 164 & $95.9 \%$ \\
\hline
\end{tabular}

Rumus perhitungan akurasi pada deteksi wajah yaitu: $[10]$

$\frac{\text { Iumlah wajah di foto + Iumlah deteksi wajah }}{\text { Iumlah wajah di foto+Iumlah deteksi wajah +Selisih }} \times 100 \%$ (1)

Berdasarkan data pada tabel 2 di atas, diperoleh akurasi sebagai berikut :

$$
\frac{170+164}{170+164+14} \times 100 \%=95.9 \%
$$

Tingkat akurasi pada deteksi wajah yaitu 95.9\%, dari perhitungan tingkat akurasi diatas dilakukan 30 kali percobaaan 
dengan gambar wajah di foto sebanyak 170 wajah jumlah foto yang terdeteksi 164 dengan selisih 14 , diantaranya ada 15 wajah dalam 1 foto yang terdekteksi wajah 14 wajah 1 wajah tidak terdeteksi karena instensitas cahaya dan bukan wajah pun terdeteksi.

Pada tahap pengujian deteksi wajah ini akan diuji berdasarkan tingkat ketepatan hasil capture dalam mendapatkan objek wajah dengan menggunakan metode Hidden Markov Model (HMM) untuk mendeteksi objek pada gambar [7].

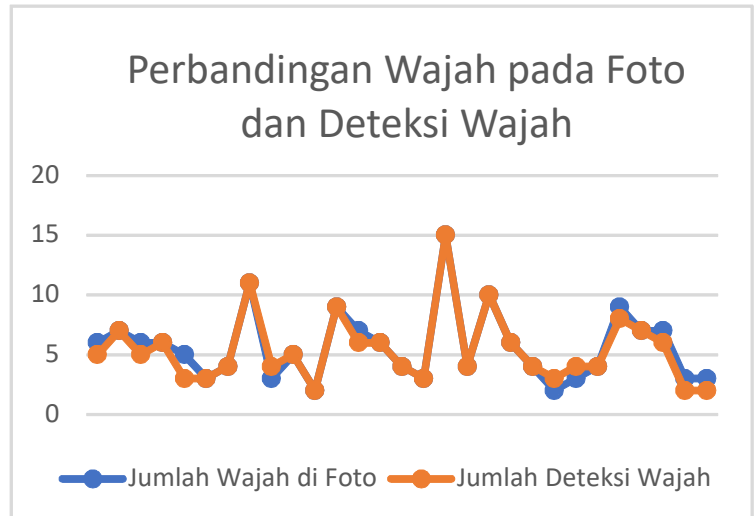

Gambar 7. Grafik Perbandingan

Pada grafik diatas digambarkan perbandingan antara nilai perbandingan wajah pada foto dan deteksi wajah dengan nilai perbandingan wajah pada foto dan deteksi wajah yang berbeda adapun yang sama juga.

\section{SIMPULAN}

Jarak antara wajah frame gambar sangat berpengaruh dalam proses pendeteksian wajah, proses pendeteksian wajah akan berjalan dengan baik bila gambar wajah terdeteksi jelas dan tidak kabur, proses yang dibangun dari sistem ini dikembangkan menurut siklus pengembangan MATLAB dan Guide MATLAB yang meliputi tahap pembuatan desain Guide, variasi ekspresi wajah bisa dikenali dengan cukup baik oleh sistem dengan tingkat akurasi pengenalan mencapai $95.9 \%$ walaupun hal ini juga tidak bersifat mutlak, karena dipengaruhi oleh beberapa faktor lain seperti telah disebutkan sebelumnya.

\section{DAFTAR PUSTAKA}

[1] Ahmad Salim Alfauzan. 2017. "Implementasi Perhitungan Deteksi Wajah Melalui Hidden Markov Model (HMM) Pada Miniboard", Jurusan Sistem Komputer, Fakultas Teknik, Universitas Telkom, Bandung.

[2] Dodi Sudiana. 2009. "Sistem Pengenalan Wajah Hidden Markov Model (HMM) Menggunakan Metode Hidden Markov Model (Hmm), Jurusan Teknik Elektro, Universitas Indonesia, Depok.

[3] M. Dwisnanto Putro, "Sistem Deteksi Wajah Dengan Menggunakan Metode Viola - Jones", Jurusan Teknik Elektro, Universitas Gajah Mada, Yogyakarta. 2012

[4] Dewi Yanti Liliana. 2013. "Deteksi Wajah Manusia Pada Citra Menggunakan Dekomposisi Fourier", Jurusan Ilmu Komputer, Universitas Brawijaya, Indonesia.

[5] Panji Purwanto. 2017. "Implementasi Face Identification Dan Hidden Markov Model (HMM) Pada Kamera Pengawas Sebagai Pendeteksi Bahaya", Jurusan Sistem Komputer, Fakultas Teknik, Universitas Telkom.

[6] Setyo Nugroho 2016. "Sistem Pendeteksi Wajah Manusia Pada Citra Digital", Jurusan Ilmu Komputer, Universitas Gajah Mada, Yogyakarta.

[7] Setya Bayu. 2016. "Penerapan Hidden Markov Model (HMM) dengan Metode Eigenface Dalam Intelligent Home Security", Jurusan Teknik Elektro, Institut Teknik Sepuluh Nopember, Surabaya. 
[8] Sehman. 2016. "Penerapan Hidden Markov Model (HMM) Dengan Metode Eigenface Pada Intelligent Car Security", Jurusan Teknologi Informasi, Teknik Sepuluh Nopember, Surabaya.

[9] Halimah. 2014. "Pengenalan Wajah Dengan Menggunakan Metode Priclpe Componen Analysis", Jurusan Informatika, Fakultas Teknik, Universitas Maritim Raja Ali Haji, Tanjung Pinang.

[10] R. Andang Gumilang. 2017. "Ekstrasi Fitur Mata Sebagai Deteksi Wajah Dengan Menggunakan Algoritma Smallest Univalue Segment Assimilating Nucleus (SUSAN)", Jurusan Informatika, Universitas Telkom.

[11]Cucu Suhery. 2013. "Identifikasi Wajah Manusia Untuk Sistem Monitoring Kehadiran Perkuliahan Menggunakan Ekstrasi Fitur PricipalComponent Analysis (PCA)", Jurusan Sistem Komputer, Fakultas MIPA, Universitas Tajungpora, Pontianak.

[12] Luthfi Maslichul Kurniawan. 2016. "Metode Hidden Markov Model (HMM) untuk Identifikasi Personil
Berdasar Citra Wajah bagi Kebutuhan Presensi Online Universitas Negeri Semarang", Jurusan Teknik Informatika, Universitas Negeri Semarang, Semarang.

[13] Meita Firdhausya. 2017. "Perancangan Sistem Pengenalan Wajah Menggunakan Transformasi Wavelet dan Hidden Markov Model", Jurusan Teknik Telekomunikasi, Fakultas Teknik Elektro, Universitas Telkom.

[14] Arie Wirawan Margono. 2015. "Pelacakan dan Pengenalan Wajah Menggunakan Metode Embedded Hidden Markov Models", Jurusan Teknik Informatika, Fakultas Teknik Industri, Universitas Kristen Petra.

[15] Wahyu Sulistyo. 2015. "Rancang Bangun Prototipe Aplikasi Pengenalan Wajah untuk Sistem Absensi Alternatif dengan Metode Haar Like Feature dan Eigenface", Jurusan Teknik Elektro, Politeknik Negeri Semarang. 